\title{
Mineralization of the central nervous system in pseudopseudohypoparathyroidism (PPH)
}

\author{
ALDEN W. DUDLEY, JR. ${ }^{1}$ AND HAL HAWKINS \\ From the Department of Pathology, Duke University School of Medicine, \\ Durham, North Carolina, U.S.A.
}

The parathyroid glands were first recognized anatomically by Remak in 1855 , fully described by Sandstrom in 1880 , and their relation to tetany described by Gley in 1891 on the basis of extirpation experiments (see Houssay, 1955; Harrison, 1962). It was not until 1908 that McCallum and Voegtlin associated hypoparathyroid tetany with lowered plasma calcium concentrations and demonstrated the reversibility of the tetany (see Harrison, 1962). Collip isolated parathormone in 1925 and described its ability to induce elevated serum calcium levels. Albright observed the concomitant effect of parathormone on serum phosphorus levels and suggested that parathormone mediates its effect by (1) increasing phosphorus excretion in urine, (2) decreasing phosphate in the serum, (3) promoting resorption of phosphorus and calcium from bones as a reaction to low serum phosphorus and by direct stimulation of osteoclasts, (4) elevating serum calcium, (5) increasing urinary output of calcium, and (6) further resorption of bone. Hypoparathyroidism thus became defined as an entity in which there was low serum calcium, high serum calcium, high serum phosphorus, and low parathormone levels. It was and is most commonly encountered as a surgical complication of thyroidectomy.

Pseudohypoparathyroidism (PH) was described in 1942 by Albright, Burnett, Smith, and Parson as a disease state in which there is a low serum calcium and high serum phosphorus but no response to parathormone administration. Because there is a latent or frank tetany that responds to intravenous calcium, it is postulated that $\mathbf{P H}$ represents an end-organ defect. A second constellation of signs has come to be identified with PH. These are: significant family history, short stature, round face, obesity, short metacarpal and/or metatarsal bones, mental deficiency, subcutaneous ossification, occasional calcification of the basal

${ }^{1}$ Present address: Department of Pathology, University of Wisconsin, Madison, Wisconsin, U.S.A. 53706. (Supported by graduate training grant in neuropathology, N.I.N.D.B., N.I.H. 2 T1 NB 5212). ganglia, and convulsions in some patients (Cusmano, Baker, and Finby, 1956; Nichols, Holdsworth, and Reinfrank, 1961; Hertzog, 1968). As might be expected, there have been patients with the skeletal, nervous, and serum alterations of PH that have produced a phosphate diuresis when challenged by parathyroid extracts (Smulyan and Raisz, 1959).

Ten years later Albright, Forbes, and Henneman (1952) described pseudopseudohypoparathyroidism (PPH) in which one sees most of the physical and mental changes alluded to above but normal serum calcium and phosphorus concentrations. Subsequent reports have shown the major differences between PH and PPH, respectively, to be: abnormal versus normal serum calcium and phosphorus levels, diagnosis made in children as opposed to young adults, infrequent instead of common exostoses, and calcification in the basal ganglia in one-third rather than one-fifth of the patients (Palubinskas and Davies, 1959: Gershberg and Weseley, 1960; Tanz, 1960; Todd, Hill, Nickerson, and Tingely, 1961 ; Cruz and Barnett, 1962; Mann, Altermann, and Hills, 1962).

The purfo:e of this paper is to describe a case of mineralization of the basal ganglia and dentate nucleus in a patient with PPH and to support the concept of the ability of some $\mathrm{PH}$ individuals to convert to the PPH syndrome as they reach the adult years. A deceased brother is also described because of the similarity in clinical history, although a diagnosis was not made during life and serum calcium and phosphorus levels were not obtained. It is significant that the parents were first cousins.

\section{CASE 1}

This 39-year-old Caucasian female (E.P.) was born in 1929. She was noted to be slow to learn and had enuresis to the age of 19. Menstruation began when she was 11 and was regular. She left school in the 11 th grade to marry and worked as an attendant at a state psychiatric hospital for 11 years. She had one male child in 1952. In 
1960 she showed such profound confusion, inattentiveness, and depression that she was released from her job and was committed by her family as a patient at a second state psychiatric hospital at 30 years of age. The working diagnoses were schizophrenia and depression. She was short (5 ft $1 \frac{1}{2}$ in.; $\left.1.5 \mathrm{~m}\right)$, obese $(217 \mathrm{lb} ; 98.4 \mathrm{~kg})$, and edentulous. The neurological examination and routine laboratory tests showed no abnormalities. After her first treatment with electro-shock therapy, she developed spontaneous convulsions intermittently for several hours. Occasional later attempts to give electro-shock therapy again provoked prolonged convulsive reactions. Urinary incontinence developed in the hospital.

In 1962 an episode of right ankle pain and swelling was diagnosed as palindronic arthritis. Radiographs of the hands and feet showed normal metacarpal and metatarsal bones, except for bilateral congenital bone cysts of the talus which were treated surgically. Multiple flecks of subcutaneous calcification were seen on radiographs of the right lower leg. In 1965 the patient developed difficulty in walking and a wide, shuffling gait. A thorough neurological evaluation was done. Radiographs of the skull showed calcifications in the pineal, choroid plexuses, and bilaterally in the region of the basal ganglia (Fig. 1). Pneumoencephalograms revealed diffuse cortical atrophy and slightly dilated lateral ventricles. The radiology consultant suggested a diagnosis of pseudopseudohypoparathyroidism. An electroencephalogram was within normal limits. Spinal fluid protein was 39 $\mathrm{mg} / 100 \mathrm{ml}$, and later in the year was $81 \mathrm{mg} / 100 \mathrm{ml}$. Eight separate serum calcium determinations from 1965 to 1968 (age 36 to 39 years) varied from 9.4 to 10.2 $\mathrm{mg} / 100 \mathrm{ml}$., serum phosphorus between 2.9 and 4.2 $\mathrm{mg} / 100 \mathrm{ml}$.

In 1967 a firm, subcutaneous mass $(6 \times 10 \mathrm{~cm})$ was noted over the patient's anterior right lower leg which was non-tender and later regressed, diagnosis unknown. Radiographs showed bilateral subcutaneous flecks of calcification in both legs. Cystic changes were noted in the antral area of the mastoid on radiography. The patient became more and more disorientated, totally incontinent, and practically bedfast. A repeat electroencephalogram showed diffuse slowing, and bilateral Babinski reflexes appeared. Faecal impaction, decubitus ulcers, and intermittent fever developed as the patient became obtunded. In May 1967, and on several occasions thereafter, spontaneous grand mal convulsions occurred. Bronchitis and bronchopneumonia developed in 1968 and, in spite of antibiotic therapy, the patient died in respiratory arrest in June 1968 at 39 years of age.

Post-mortem examination of the brain revealed a weight of only $850 \mathrm{~g}$ due to diffuse cortical atrophy with hydrocephalus ex vacuo. The medial superior portion of the globus pallidus, measuring $1.0 \times 0.8 \times 0.5 \mathrm{~cm}$ and abutting the internal capsule, was discoloured brownblack on fresh coronal sections of the formalin-fixed brain (Fig. 2). This same area was the sole site (other than the pineal gland and choroid plexus) of radiopacity in the fixed brain (Fig. 3). Microscopy revealed scattered metallic concretions, averaging $20 \mu$ in diameter, present throughout the medial superior portion of the globus pallidus and, to a lesser extent, the dentate nuclei. They

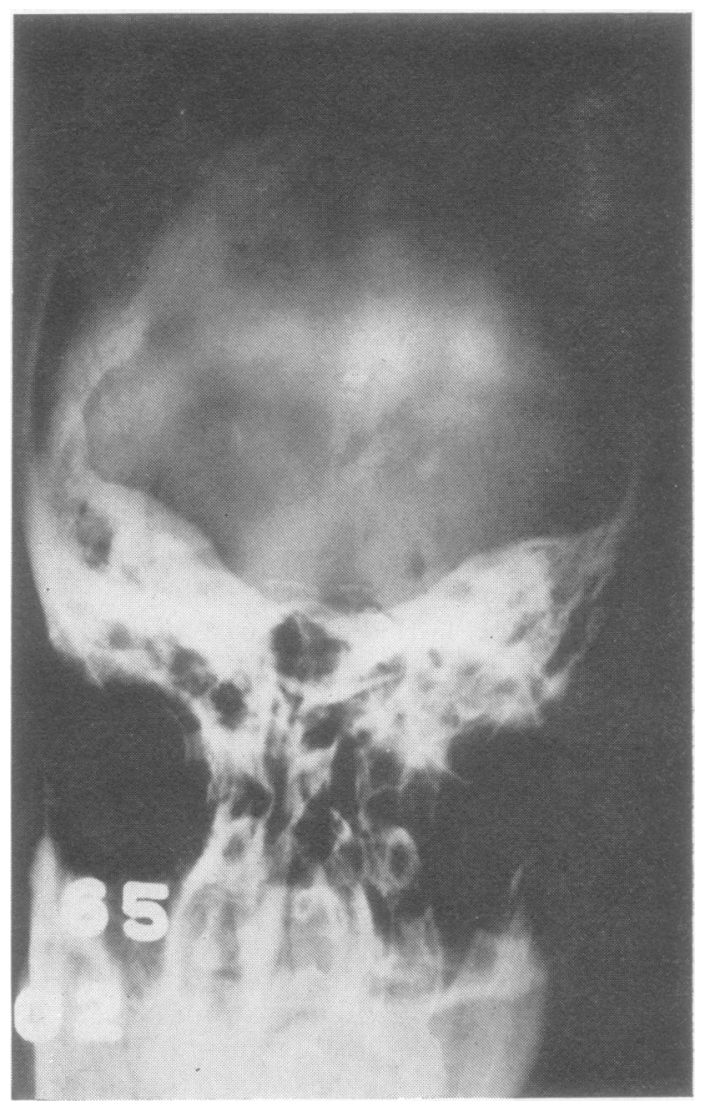

FIG. 1. Plain skull film showing calcification of pineal gland, choroid plexus (right only) and globus pallidus (bilateral).

were not associated with vascular structures. Specia stains for iron (Fig. 4) and calcium (Fig. 5), with controls, gave a strong reaction for both metals in the granules. Techniques for the analysis for trace metals were not available. The choroid plexus showed normal calcification which stained strongly for calcium but not for iron. The thoracic spinal cord demonstrated partial demyelination of the medial posterior columns. The brain did not show any foci of demyelination.

The remainder of the examination revealed confluent bronchopneumonia bilaterally as the cause of death. Submucosal haemorrhages were present throughout the gastrointestinal tract, and the entire colon was markedly distended with impacted faeces. All other organs were normal grossly and microscopically. Two normalappearing parathyroid glands were identified. The pancreas, adrenals, thyroid, and pituitary showed no abnormalities.

\section{CASE 2}

This 33-year-old Caucasian male (J.R.), the brother of case 1, was born in 1924 . He was noted to develop 


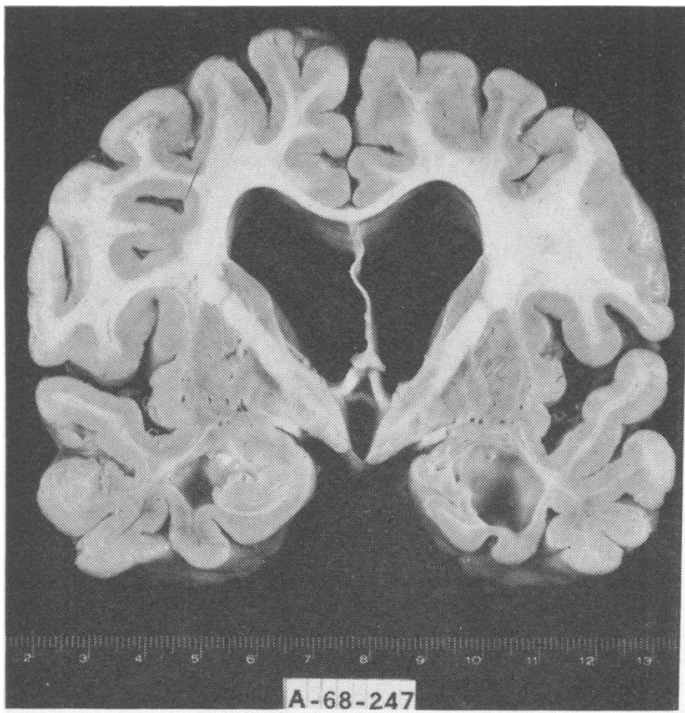

FIG. 2. Coronal section of brain showing diffuse atrophy, secondary ventricular dilatation, and brown-black superior medial segment of the globus pallidus.

abnormally from early childhood, required frequent formula changes, and grew very slowly. He was diagnosed as having rickets at 4 months of age. He first spoke at age $2 \frac{1}{2}$ years and began to walk at 3 . He suffered frequent night terrors. He began school at the age of 7 and socialized well, but dropped out after failing the fourth grade twice. Seizures consisting of stiffening for several minutes without loss of consciousness, sometimes with a tremor, began to occur at the age of 12 about once a week. Later they became grand mal in character, preceded by an aura, and followed by stupor. Phenytoin (Dilantin) and phenobarbital therapy failed to control these convulsive episodes.

Physical examination revealed multiple abnormalities. At 13 years of age his height was $129 \mathrm{~cm}$ (average $146 \mathrm{~cm}$ ); at 27 years he was $165 \mathrm{~cm}(5 \mathrm{ft} 5 \mathrm{in}$.) tall but not obese. His fingers were short and stubby and the fifth finger on each hand was disproportionately short. His head was oxycephalic. The optic discs were pale, and hypertelorism was noted. The nose was flat and flaring, somewhat negroid. The palate was high and arched, and the patient consistently breathed through his mouth. He had a receding chin, and his teeth did not approximate. The chest showed costal flaring, with a slight Harrison's groove. The neurological examination was normal except for mental retardation; his tested IQ was 53. A pneumoencephalogram at the age of 13 revealed dilated lateral ventricles and generalized cortical atrophy but no intracranial calcifications were recognized at that time. The spinal fluid was at $200 \mathrm{~mm}$ water pressure and contained protein $40 \mathrm{mg} / 100 \mathrm{ml}$., NPN $14 \mathrm{mg} / 100 \mathrm{ml}$., and sugar $80 \mathrm{mg} / 100 \mathrm{ml}$.

The patient was committed to a state mental hospital at 27 years of age because of his epilepsy and retardation.

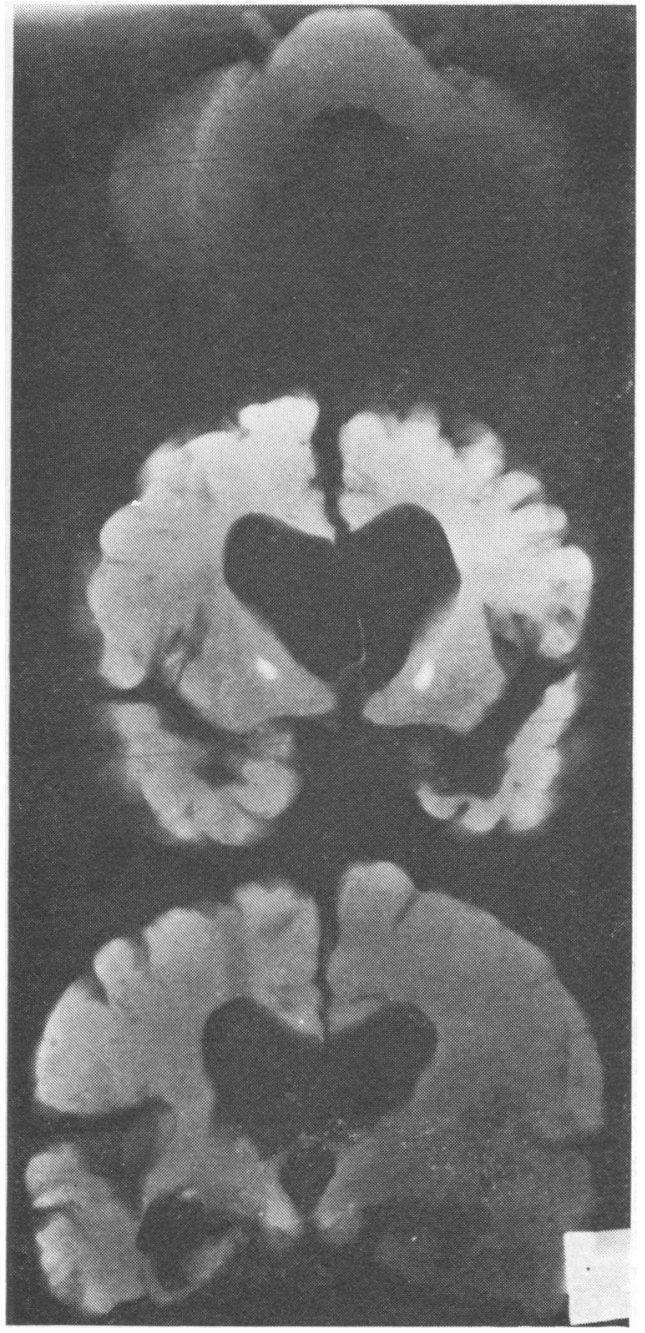

FIG. 3. Post-mortem radiographs of coronal sections of the brain. Upper: cerebellum devoid of opacities in dentate nucleus. Middle: dense mineralization of globus pallidus (correlate with Fig. 2). Lower: unilateral calcification of choroid plexus as in Fig. 1.

Records are incomplete and, unfortunately, no serum calcium determination is available. His course in the hospital was slowly downhill with diagnoses of idiopathic epilepsy, mental retardation, and diffuse cortical atrophy. He died in June 1957 of bronchopneumonia. In retrospect his short fingers, poor growth, and mental retardation implicate the syndrome of either PH or PPH.

\section{DISCUSSION}

Because of the remarkable similarities between $\mathbf{P H}$ and PPH, it has been suggested by several authors 


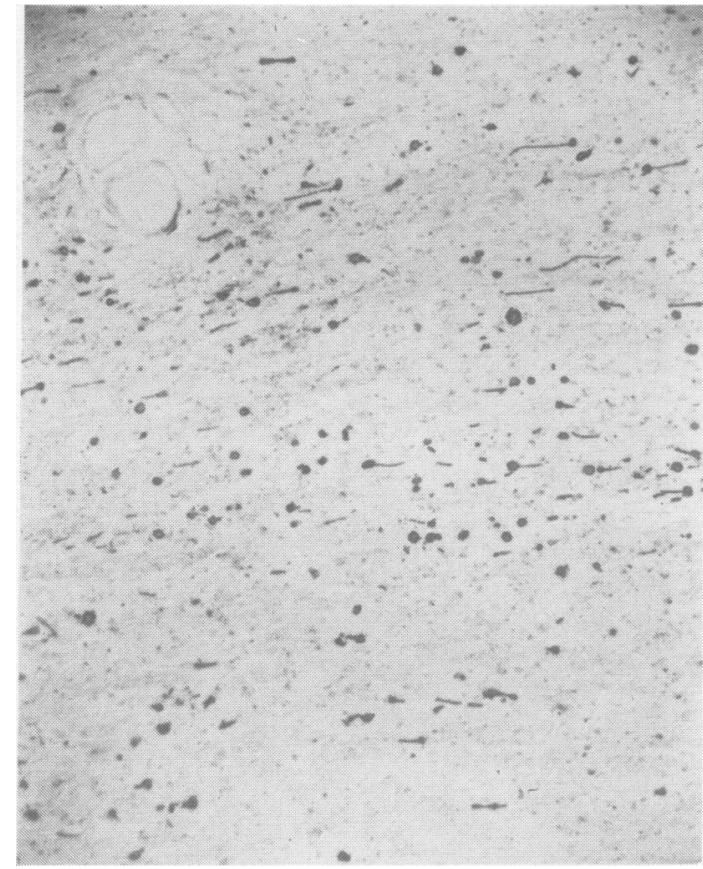

FIG. 4. Dense iron deposits in region of globus pallidus. Turnbull blue, $\times 35$.

that the two are separate genetic factors which may penetrate independently. Steinbach and Young (1966) have suggested that $\mathrm{PH}$ includes three independent genetic constituents: (1) skeletal malformationsthat is, short stature and short metacarpals, (2) calcification of soft tissues, and (3) abnormal calcium levels in serum. Thus, PPH would be incompletely penetrant $\mathrm{PH}$ in which the third component is lacking. The frequent mental retardation might be another separate genetic trait or may be the consequence of the effect of electrolyte imbalance on the central nervous system.

Several cases have been reported of PH and PPH occurring in the same family (Dickson, Morita, Cowsert, Graves, and Meyer, 1960; Gershberg and Weseley, 1960; Todd et al., 1961; Hermans, Gorman, Martin, and Kelly, 1964; Hinkle, Travis, and Dodge, 1964) and of isolated features of $\mathrm{PH}$ in families with well-documented PPH (Cruz and Barnett, 1962; Hermans et al., 1964). Other cases have been reported which seem to change in the course of the disease from one syndrome to the other (Palubinskas and Davies, 1959; Ray and Gardner, 1959; Hinkle et al., 1964). Gershberg and Weseley (1960) reported two cases of reversion from abnormally low to normal serum calcium, with advancing age, in a patient with PH. Palubinskas and Davies (1959) reported an interesting

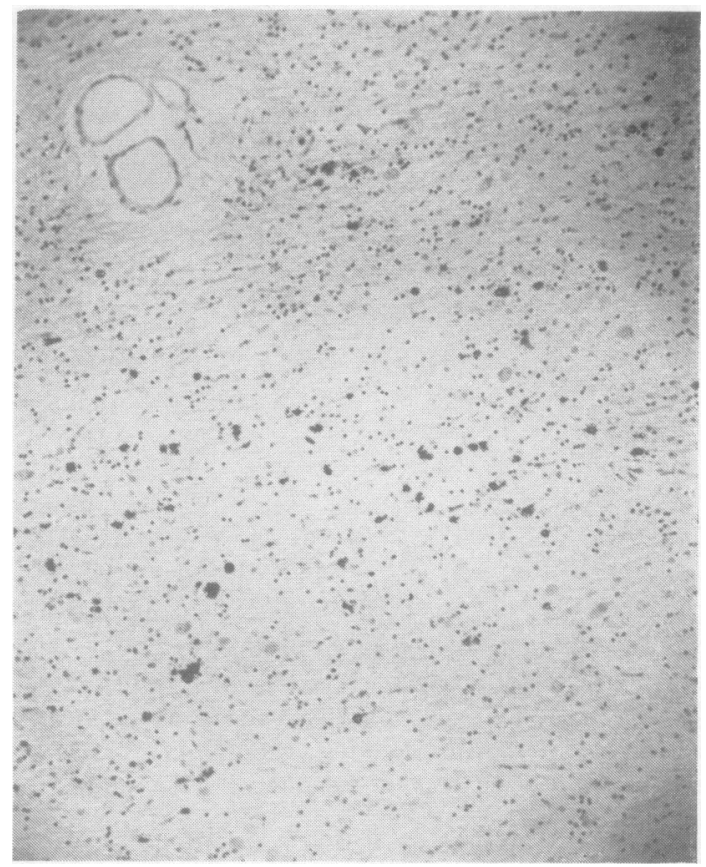

FIG. 5. Calcium deposits in same histological field. Von Kossa, $\times 35$.

girl who had short metacarpals, soft tissue calcifications, genu valgum, and serum calcium $4.5 \mathrm{mg} / 100$ $\mathrm{ml}$. at 8 years of age. She also was retarded, short, obese, had convulsions, but did not have any known intracranial calcifications. At age 21 she was found to have normal serum calcium, with no therapy, and radiographs revealed bilateral calcifications of the basal ganglia. Her mother also had PPH. The fact that $\mathbf{P H}$ is typically a disease of children, whereas PPH is characteristically found in adults, has led to the postulate that the diseases are the same, but that metabolic stress, such as growth in children or pregnancy in young women with an increased demand for calcium, may cause temporary hypocalcaemia (Gershberg and Weseley, 1960).

Calcification of the basal ganglia to an extent detectable by radiographs of the skull is a rare entity except in $\mathrm{PH}$ where fully one-third of the patients manifest this change. By contrast, PPH has only two reported instances (Palubinskas and Davies, 1959; Tanz, 1960) of mineralization of the basal ganglia detected clinically with no opportunity for a post-mortem analysis. At least 75 cases of PPH have been described in which there was no known involvement of the basal ganglia (Albright et al., 1952; Miles and Elrick, 1954; Roche, 1955; McNeely, Raisz, and Le May, 1956; Seringe and Tomkiewicz, 
1956; Wallach, Englert, and Brown, 1956; Bronsky, Kushner, Dubin, and Snapper, 1958; Casey, Fast, and Cherniack, 1959; Ray and Gardner, 1959; Rubinstein and Cody, 1959; Barr, Taylor, and Rabkin, 1960; Dickson et al., 1960; Gershberg and Weseley, 1960; Hortling, Puupponen, and Koski, 1960; Tanz, 1960; Ahmed, 1961; Gibson, 1961; Schwarz, 1961 ; Todd et al., 1961; Uhr and Bezhaler, 1961 ; Cruz and Barnett, 1962; Hermans et al., 1964; Hinkle et al., 1964; Becker, Hoffman, Hermans, and Martin, 1965; Jancar, 1965; Schaaf, Wagner, and Schwarz, 1966; Morisaki, Sugawara, and Yoon, 1967; Emanuelli and Pellegrini, 1968; Kelly, 1968). The demonstration by Palubinkas and Davies (1959) of conversion of a $\mathrm{PH}$ patient without calcification to a PPH syndrome with mineralization of the basal ganglia is quite important. It offers an explanation for the potential development of calcification in an unrecognized $\mathrm{PH}$ patient that may be subsequently correctly diagnosed as PPH. This is thought to be the mechanism operative in our case 1 .

Classification of case 1 as a PPH is felt to be justified in the absence of wrist or ankle anomalies because of a multitude of other symptoms and signs present in this patient. Contrary to the suggestion by Fromm (1956) that all cases to be diagnosed as PPH adhere strictly to the initial description by Albright et al. (1942), Papaioannou and Matsas (1963) have shown in a review of 41 cases in the literature that there is no sine qua non. The incidence of diagnostic features discussed by Papaioannou is as follows: short metacarpals or metatarsals $(92 \%)$, short stature $(76 \%)$, round face $(71 \%)$, mental retardation $(64 \%)$, obesity $(61 \%)$, ectopic calcinosis $(35 \%)$, and exostoses $(23 \%)$. Case 1 had all of the above except short wrist or ankles and also demonstrated the commonly associated features of convulsions, family history of a sibling with short metacarpals, diagnosis made during adulthood, and mineralization of the basal ganglia. It is considered probable that the patient would have shown altered serum calcium and phosphorus levels had she been examined while a child. She was already 23 years of age at the time of Albright et al's original case report (1952).

Case 2 demonstrated multiple skeletal and mental signs of PH and PPH but did not have serum analyses for calcium or phosphorus. The short metacarpals make the diagnosis quite secure. The progressive mental deterioration seen in both cases and frequently described in both PH and PPH was due to a severe generalized atrophy of all portions of the brain.

The term 'mineralization' of the basal ganglia has been used to describe the necropsy findings of both calcium and iron in the globus pallidus and dentate nuclei rather than pure calcium. Recent reports of electron probe (activation) analysis of intracranial mineral deposits suggest that such deposits are rarely homogeneous (Leestma, Wisniewska, and Martin, 1969). Phosphorus, sulphur, and trace elements, such as zinc and cobalt, have been identified in various concentrations in different areas of the same plaque. Thus, 'mineralization' is a more generic and proper term for cases previously classified simply as 'calcification'.

SUMMARY

Bilateral mineralization of the globus pallidus and dentate nuclei in a patient with pseudopseudohypoparathyroidism (PPH) is described and discussed. The concretions were found to contain both calcium and iron in high concentrations. Reports of conversion of patients from pseudohypoparathyroidism (PH) to $\mathrm{PPH}$, the greater frequency of mineralization of basal ganglia in $\mathrm{PH}$, and the absence of serum calcium and phosphorus determinations from the patient during childhood allow the possibility that the patient under discussion developed calcification while in the $\mathrm{PH}$ stage and subsequently converted to PPH. The presence of one sibling with either $\mathrm{PH}$ or PPH and other normal siblings as the products of a marriage of first cousins suggests a recessive mode of inheritance. The mental retardation of increasing severity in both siblings is related to a progressive generalized atrophy of the cerebral hemispheres and cerebellum.

\section{REFERENCES}

Ahmed, S. (1961). Pseudo-pseudohypoparathyroidism. Report of two new cases. Brit. J. clin. Pract., 15, 585-592.

Albright, F., Burnett, C. H., Smith, P. H., and Parson, W. (1942) Pseudo-hypoparathyroidism: an example of the SeabrightBantam syndrome. Endocrinology, 30, 922-932.

- Forbes, A. P., and Henneman, P. H. (1952). Pseudo-pseudohypoparathyroidism. Trans. Ass. Amer. Phycns., 65, 337-350.

Barr, S. E., Taylor, E. F., and Rabkin, B. (1960). Pseudo-pseudohypoparathyroidism: Report of a case and review of the literature. Arch. intern. Med., 105, 492-495.

Becker, K. L., Hoffman, D. L., Hermans, P. E., and Martin, W. J. (1965). Pseudo-pseudohypoparathyroidism (brachymetacarpal dwarfism): Endocrinologic studies on a patient. Minn. Med. 48, 186-190.

Bronsky, D., Kushner, D. S., Dubin, A., and Snapper, I. (1958) Idiopathic hypoparathyroidism and pseudohypoparathyroidism. Medicine (Baltimore), 37, 317-352.

Casey, 1. R., Fast, B. B., and Cherniack, R. M. (1059). Pseudopseudohypoparathyroidism: Report of a case with associated cardiopulmonary syndrome of obesity. J. Amer. med. Ass., 169 1988-1990.

Collip, J. B (1925). The parathyroid glands. Harvey Lect., 21, 113-172.

Cruz, C. E., and Barnett, N. (1962). Mental retardation in pseudopseudohypoparathyroidism: Case reports of siblings and review of the literature. Amer. J. ment. Defic., 67, 381-395.

Cusmano, J. V., Baker, D. H., and Finby, N. (1956). Pseudohypoparathyroidism. Radiology, 67, 845-853.

Dickson, L. G., Morita, T., Cowsert, E. J., Graves, J., and Meyer, J. S. (1960). Neurological, electroencephalographic, and heredofamilial aspects of pseudohypoparathyroidism and pseudopseudohypoparathyroidism. J. Neurol. Neurosurg. Psychiat. 23, 33-39. 
Emanuelli, G., and Pellegrini, A. (1968). Su un caso di pseudopseudoipoparatirodismo con osteite fibrosa diabete mellito e diabete insipido. Minerva med., 59, 681-689.

Fromm, G. A. (1956). Concerning the term 'pseudo-pseudohypoparathyroidism.' J. clin. Endocr., 16, 293-295.

Gershberg, H., and Weseley, A. C. (1960). Pseudohypoparathyroidism and pregnancy: Is pseudo-pseudohypoparathyroidism a mild form of pseudohypoparathyroidism? J. Pediat., 56, 383-386.

Gibson, R. (1961). Brachymetacarpal dwarfism of pseudo-pseudohypoparathyroidism with mental defect in siblings. Canad. med. Ass. J., 85, 70-72.

Harrison, T. R. (ed.) (1962). For references to Sandstrom (1880), Gley (1891) and McCallum and Voegtlin see D. S. Bernstein A. Goldfien and A. W. Thorn, Diseases of the parathyroid glands in Principles of Internal Medicine, p. 599, 4th edition. McGraw Hill: New York.

Hermans, P. E., Gorman, C. A., Martin, W. J., and Kelly, P. J. (1964) Pseudo-pseudohypoparathyroidism (Albright's hereditary osteociystrophy): a family study. Mayo Clin. Proc., 39, 81-91.

Hertzog, K. P. (1968). Brachydactyly and pseudo-pseudohypoparathyroidism. Acta Genet. med. (Roma), 17, 428-438.

Hinkle, D. O., Travis, L. B., and Dodge, W. F. (1964). Albright's hereditary osteodystrophy in a mother and daughter. Tex. Rep. Biol. Med., 23, 463-473.

Hortling, H., Puupponen, E., and Koski, K. (1960). Short metacarpal or metatarsal bones: pseudo-pseudohypoparathyroidism. $J$. clin. Endocr., 20, 466-472.

Houssay, B. A. (ed.) (1955). For references to Remak (1855), Sandstrom (1880), and Gley (1891) see Human Physiology, p. 627, 2nd edition. McGraw Hill: New York.

Jancar, J. (1965). Cerebro-metacarpo-metatarsal dystrophy (pseudopseudohypoparathyroidism) with chromosomal anomaly. $J$. med. Genet., 2, 32-37.

Kelly, J. J. (1968). Albright's hereditary osteodystrophy associated with disc calcification and bilateral dislocation of the hips. Brit. J. clin. Pract., 22, 399-403.

Leestma, J., Wisniewska, K., and Martin, E. (1969). Electron probe analysis of mineral deposits in the central nervous system. $J$. Neuropath. exp. Neurol., 28, 157.

Mann, J. B., Altermann, S., and Hills, A. G. (1962). Albright's hereditary osteodystrophy comprising pseudohypoparathyroidism and pseudopseudohypoparathyroidism: with a report of two cases representing complete syndrome occurring in successive generations. Ann. intern. Med., 56, 315-342.

McNeely, W. F., Raisz, L. G., and Le May, M. (1956). Dyschondroplasia with soft tissue calcification and ossification and normal parathyroid function (Pseudo-pseudohypoparathyroidism). Amer. J. Med., 21, 649-656.

Miles, J., and Elrick, H. (1954). Pseudo-pseudohypoparathyroidism: report of new case. J. clin. Endocr. 15, 576-584.

Morisaki, N., Sugawara, S., and Yoon, Y. (1967). A case of pseudopseudohypoparathyroidism (Albright). Endocr.jap., 14,327-332.

Nichols, F. L., Holdsworth, D. E., and Reinfrank, R. F. (1961). 6 Familial hypocalcemia, latent tetany, and calcification of the $T$ basal ganglia. Report of a kindred. Amer. J. Med., 30, 518.

Palubinkas, A. J., and Davies, H. (1959). Calcification of the basal ganglia of the brain. Amer. J. Roentgenol., 82, 806-822.

Papaionnou, A. C., and Matsas, B. E. (1963). Albright's hereditary osteodystrophy (without hypocalcemia). Pediatrics, 31, 599-607.

Ray, E. W., and Gardner, L. I. (1959). Pseudo-pseudohypoparathyroidism in a child. Ibid., 23, 520-529.

Roche, M. (1955). Case of pseudo-pseudohypoparathyroidism. J. clin. Endocr., 15, 964-969.

Rubinstein, E., and Cody, R. (1959). Pseudo-pseudohypoparathyroidism with dense calcification of the aorta. Report of a case. Stanf. med. Bull., 17, 171-174.

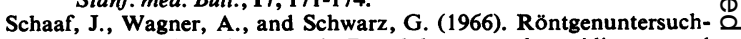
ungen bei Patienten mit Pseudohypoparathyreoidismus und Pseudo-Pseudohypoparathyreoidismus. I. Röntgensymptome. Fortschr. Röntgenstr., 105, 877-886.

Schwarz, G. (1961). Zur Pathogenese des Pseudo-Pseudohypoparathyreoidismus. Dtsch. med. Wschr., 86, 257-259.

Seringe, PH., and Tomkiewicz, S. (1956). Pseudo-pseudo-hypoparathyroidisme familial. Ann. Endocr., 17, 655-664.

Smulyan, H., and Raisz, L. G. (1959). Pseudo-pseudohypoparathyroidism with unusual features. J. clin. Endocr., 19, 478-484.

Steinbach, H. L., and Young, D. A. (1966). The roentgen appearance? of pseudohypoparathyroidism (PH) and pseudo-pseudo- $\omega$ hypoparathyroidism (PPH). Amer. J. Roentgenol., 97, 49-66. $\square$

Tanz, S. S. (1960). Pseudo-pseudo-hypoparathyroidism. Three cases in one family. Amer. J. med. Sci., 239, 453-461.

Todd, J. N. III, Hill, S. R., Jr., Nickerson, J. F., and Tingely, J. \&. (1961). Hereditary multiple exostoses, pseudo-pseudohyp parathyroidism and other genetic defects of bone, calcium, ant phosphurus metabolism. Amer. J. Med., 30, 289-298.

Uhr, N., and Bezhaler, H. B. (1961). Pseudo-pseudohypoparathyroidism: report of three cases in one family. Ann. intern. Me\&, $54,443-451$.

Wallach, S., Englert, E., Jr., and Brown, H. (1956). The syndrome ff pseudo-pseudohypoparathyroidism. Arch. intern. Med., 517-524. 